\title{
Comunicação entre acadêmicos surdos e ouvintes na mediação da aprendizagem no ensino superior
}

\author{
Krysne Kelly de França Oliveira ${ }^{\mathrm{a}, \mathrm{b}}$, Chrystiane Maria Veras Pôrto ${ }^{\mathrm{b}}$ \\ aUniversidade Estadual do Ceará - UECE, Fortaleza, CE, Brasil

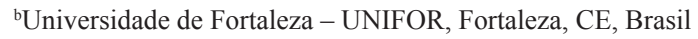

\begin{abstract}
Resumo: Introdução: Há um avanço na quantidade de surdos com acesso ao ensino superior. Na sua maioria, são jovens que, com uma cultura diferente, enfrentam dificuldades de comunicação, inter-relação e aprendizagem na cultura ouvinte, pois assumem uma língua diferente dos demais, a Língua Brasileira de Sinais - Libras. Objetivo: A pesquisa buscou identificar as formas de comunicação utilizadas entre acadêmicos surdos e ouvintes, verificando como essas podem interferir no processo de aprendizagem. Procedimentos metodológicos: O estudo, de natureza qualitativa, utilizou o espaço de uma universidade particular no município de Fortaleza, Ceará, no período de fevereiro a abril de 2009. Foram efetivadas entrevistas semiestruturadas com três acadêmicos surdos, três professores, três intérpretes e três acadêmicos ouvintes. O conteúdo das falas foi categorizado e organizado pelo método Análise Temática. Resultados: Constatou-se que as formas de comunicação utilizadas vão desde a mímica e gestos até a escrita e o desenho, porém, a mais aceita pelo surdo é a Libras. Essa, como método de comunicação, é favorável à aprendizagem do acadêmico surdo e, com a mediação do intérprete, dá condições ao surdo de se estabelecer em suas zonas de desenvolvimento, segundo os preceitos de Vygotsky. Conclusão: Por fim, é reconhecida a relevância da Libras como língua majoritária e fundamental ao pleno desempenho acadêmico do surdo, porém o esforço e dedicação dele, assim como o interesse da instituição e de professores quanto à cultura surda também são importantes à formação do futuro profissional.
\end{abstract}

Palavras-chave: Surdez, Educação Superior, Aprendizagem.

\section{Communication between hearing impaired and normal hearing students: a facilitative proposal of learning in higher education}

\begin{abstract}
Introduction: There has been an increase in the number of hearing impaired people with access to higher education. Most of them are young people from a different culture who present difficulties in communication, inter-relationship, and learning in a culture of normal hearing people, because they use a different language, the Brazilian Sign Language - LIBRAS. Objective: The present study aimed to identify the forms of communication used between hearing impaired and normal hearing students, verifying how they can interfere with the learning process of the first. Methods: A qualitative study that used the space of a private university in the city of Fortaleza, Ceará state, Brazil, from February to April 2009. We carried out semi-structured interviews with three hearing impaired students, three teachers, three interpreters, and three normal hearing students. The content of the speeches was categorized and organized by the method of thematic analysis. Results: We verified that the forms of communication used ranged from mime and gestures to writing and drawing, but the most accepted by the hearing impaired students was LIBRAS. As a method of communication, it supports the learning of hearing impaired students, and with the mediation of interpreters, it gives them conditions to settle in their zones of development, according to the precepts of Vygotsky. Conclusion: Thus, we recognize the importance of LIBRAS as predominant language, essential to the full academic achievement of hearing impaired students; however, their efforts and dedication, as well as the interest of institutions and teachers on the deaf culture, are also important for preparing future professionals.
\end{abstract}

Keywords: Hearing Impairment, Higher Education, Learning.

Autor para correspondência: Chrystiane Maria Veras Porto, Universidade de Fortaleza, Av. Washington Soares, 1321, CEP 60811-905, Fortaleza, CE, Brasil, e-mail: chrysporto@unifor.br

Recebido em 12/7/2012; $1^{\text {a }}$ Revisão em 2/10/2013; $2^{a}$ Revisão em 20/2/2014; Aceito em 22/5/2014. 


\section{Introdução}

A aprendizagem é tomada por conceitos que muitas vezes a situam em um estreito elo com um espaço físico determinado, quer seja a escola, a universidade ou a própria sala de aula. Nesses espaços é que se constituem as trocas de informaçóes, onde ocorre assimilação de conteúdos, formula-se saber e se desenvolve cognitivamente.

Gil (2002) refere que no ensino superior a aprendizagem acontece com origem nas interaçôes, autodireção, situação-problema e satisfação, que irão determinar a evolução do saber e das habilidades mentais do acadêmico. Considerando a informação, pode-se questionar como esse processo acontece para a pessoa surda, ou seja, como a alteração na audição interfere na comunicação e aprendizagem dessas pessoas.

Marostega e Santos (2006) inferem sobre essa informação quando se reportam à teoria sociointeracionista de Vygotsky, expressando que a aprendizagem ocorre por meio das interações sociais e que essa, por sua vez, acontece mediante a comunicação, com uma língua expressa e compreendida.

Os surdos apresentam grandes problemas quando necessitam ser incluídos no grupo de ouvintes no ambiente escolar, com interação e comunicação, haja vista náo dominarem a mesma forma de linguagem desses e, por esse motivo, muitos se encontram distantes da realidade do espaço universitário. Essa realidade, entretanto, se modifica paulatinamente, e os surdos estấo cada vez mais presentes nas instituiçôes de ensino superior.

Segundo dados do Ministério da Educação (BRASIL, 2009), o Instituto Nacional de Estudos e Pesquisas Educacionais Anísio Teixeira (INEP) contabilizou em 200920.019 matrículas de alunos com necessidades educacionais especiais no ensino superior, correspondendo a $0,34 \%$ do total. Dentre esses, aqueles com deficiência auditiva constituiram $22 \%$ dos alunos no ensino superior.

Muitas podem ser as dificuldades de aprendizagem enfrentadas pelo surdo dentro do espaço acadêmico, iniciando pela ausência da linguagem oral, desconhecimento dos educadores e acadêmicos ouvintes quanto à Língua Brasileira de Sinais (Libras) - língua materna dos surdos utilizada no Brasil - e consequente dificuldade de comunicação.

Consoante Smole e Diniz (2002), é por intermédio da comunicação que informações e conceitos são repassados entre as pessoas, sendo a comunicaçáo oral o recurso mais acessível, ágil e direto, que permite a convivência dos alunos entre si e a consequente aprendizagem coletiva mediante o exercício da escuta entre os que se relacionam. Admite-se a comunicação como um processo ocorrente em duas vias, sendo necessário um entendimento daquilo que foi dito por ambos os participantes da informação, ou seja, não há comunicação quando o receptor náo compreende o que lhe foi revelado.

Munguba (2002) exprime que Vygotsky faz consideraçóes sobre os processos de aprendizagem, ressaltando que, pela interferência de outrem (mediação) são fornecidas possibilidades ao processo de maturação.

De acordo com a autora retrocitada, Vygotsky refere uma zona de desenvolvimento real, caracterizada pela capacidade de a pessoa executar atividades de modo independente. A zona de desenvolvimento potencial, também estudada pelo autor bielo-russo, envolve habilidades que se apresentam em formação. $\mathrm{Na}$ terceira zona, a de desenvolvimento proximal vygotskyana, é mantida relação com as duas outras, referindo-se às habilidades em decurso de viabilização, requerendo níveis de ajuda - mediação - que permitirão alcançar as outras zonas.

Por via da mediação, que poderá ser realizada por intercessão de uma pessoa, se adquirem conhecimento e experiências necessárias à formação psíquica do indivíduo, ou seja, se produz aprendizado. Questiona-se como a comunicação, baseada na inter-relação de alunos surdos e ouvintes, interfere no aprendizado daqueles, sabendo-se das limitaçôes que demonstram quanto à linguagem oral.

Como já referido, o surdo não possui a linguagem oral e, mesmo quando oralizado, ainda existem dificuldades por parte dos ouvintes quanto à compreensão. A linguagem utilizada primordialmente pelo surdo é a linguagem das mãos, dos gestos ou a Libras, e essa também não é compreendida ou difundida na maioria dos espaços acadêmicos, o que promoverá um deficit comunicativo nessa relação.

A cultura de uma sociedade é dada pelas características dela, seus valores, crenças, costumes, hábitos, religiōes, leis e língua utilizada. Lacerda (2006) acrescenta que, de acordo com a cultura surda, a língua de sinais é inerente ao indivíduo surdo e deve ser adquirida antes de uma segunda língua (oral).

Dizeu e Caporali (2005) ressaltam que a língua de sinais possui um relevante papel na vida do sujeito surdo, constituído das necessidades deles quanto à comunicação e interação social, porquanto apresentam dificuldades na aquisição da língua oral. A língua de sinais, ainda destacam as autoras, 
é adquirida de modo fácil e rápido pelo surdo, fornecendo a ele a oportunidade de se comunicar, expressar e pensar.

Considerando as inferências acerca do conteúdo e todo o seu detalhamento, julga-se necessário, mediante o constante acréscimo dos alunos surdos ao ensino superior, analisar como acontece a comunicação entre os acadêmicos surdos e ouvintes e seus impactos sobre a aprendizagem do surdo no contexto da educação superior.

\section{Método}

A investigação de que se cuida é um estudo de natureza qualitativa (MINAYO, 2006), do tipo descritivo (RAMPAZZO, 2004) e de campo (CAMPOS et al., 2001), tendo como cenário da pesquisa uma instituição particular de ensino superior, localizada na cidade de Fortaleza, Ceará, no período de fevereiro a abril de 2009.

Os sujeitos da pesquisa compuseram um grupo de 12 pessoas, sendo três acadêmicos surdos e três ouvintes, matriculados nos cursos de Terapia Ocupacional, Fisioterapia e Administração da universidade focalizada. Os alunos cursavam o quinto, o segundo e o primeiro semestre. Participaram também os três professores que ministravam as disciplinas cursadas pelos alunos da pesquisa e três intérpretes ${ }^{1}$ de Libras, inseridos no contexto dos alunos surdos no mesmo período. É importante ressaltar que náo foi feita distinção de gênero entre os participantes, sendo eles tomados de forma aleatória.

A coleta de dados ocorreu, inicialmente, com a identificação das disciplinas cursadas pelos sujeitos da pesquisa no primeiro semestre letivo do ano de 2009, dessas foram selecionadas: Processos Clínicos e Cirúrgicos, Recursos Fisioterapêuticos I e Administração I. Esse procedimento favoreceu um detalhamento nas observações, tendo em vista que algumas disciplinas são práticas e poderiam modificar a didática do professor, assim como dificultar ou facilitar o processo de aprendizagem e comunicação do aluno surdo.

Em seguida foi realizada a observação sistemática no ambiente de sala de aula/campo por meio de roteiro adaptado da disciplina Terapia Ocupacional nas Deficiências Sensoriais, do curso de Terapia Ocupacional da instituição referida. O intuito foi adquirir dados sobre a adaptaçáo do aluno surdo à rotina e espaço físico, seu relacionamento com professores e colegas, desempenho acadêmico, comunicação, possíveis modificaçôes no ambiente, tarefa ou pessoa e os níveis de ajuda utilizados por professores e colegas de turma. A observaçáa sistemática aconteceu três vezes por semana, sendo um dia para cada aluno participante da pesquisa, no período de fevereiro a abril do ano de 2009 , totalizando nove dias de observação para cada aluno, do início ao fim de cada aula.

Por fim, ao final do período de observação, foram aplicados os roteiros de entrevista aos participantes. As entrevistas semiestruturadas continham questóes norteadoras para ouvintes (professores, alunos e intérpretes) e acadêmicos surdos. Essas constituíram os principais objetos de estudo para fomentar as questôes advindas da análise dos dados, resultando na composiçáo do tópico que nesse estudo se insere - resultados e discussôes. Já as observaçôes realizadas no contexto da sala de aula auxiliaram o pesquisador a discorrer sobre o assunto e confrontar dados com o conteúdo relatado nas entrevistas, fazendo uma análise mais crítica sobre as temáticas geradas.

Elegeu-se como técnica de análise dos dados a Análise de Conteúdo (BARDIN, 1997), cuja modalidade ocorre como análise temática. Mediante a escolha dessa abordagem foi necessária a operacionalidade em três etapas, iniciando-se pela leitura flutuante de todo o material, a constituição do corpus, formulação e reformulação de hipóteses e objetivos. No segundo momento fez-se a exploração do material com o intuito de encontrar categorias e organizar o conteúdo das falas. Na terceira e última etapa incluiram-se o tratamento dos resultados e sua interpretação.

Os partícipes do estudo aceitaram toda a proposta da pesquisa e foram devidamente esclarecidos acerca de seus direitos, conforme os referenciais básicos da Bioética, constantes da resolução n. 196/96 do Conselho Nacional de Saúde, reguladora de pesquisas com seres humanos, sendo submetido o seu plano ao Comitê de Ética da instituição em que ocorreu o estudo, tendo sido aprovado o projeto sob o parecer número 395/08.

\section{Resultados e discussão}

Com suporte nas observaçóes realizadas no contexto universitário, na leitura e análise das expressóes extraídas das entrevistas com os participantes do estudo, emergiram categorias temáticas que nortearam a discussão.

Os aspectos citados levam à caracterização das falas dos sujeitos diretamente relacionados à aprendizagem do acadêmico surdo e trazem perspectivas acerca das formas de comunicação utilizadas entre surdos e ouvintes, da relevância da língua de sinais para 
construção do conhecimento do acadêmico surdo, suas dificuldades no que concerne ao processo escolar, assim como dos ouvintes para com a forma de comunicação utilizada por ele. Para facilitar a compreensão do leitor, os participantes da pesquisa serão designados como: acadêmicos surdos (AS), intérprete $(\mathrm{I})$, professor $(\mathrm{P})$ e acadêmico ouvinte $(\mathrm{AO})$, todos numerados na ordem de um a três, conforme a quantidade de participantes explicitada nos métodos.

\subsection{Formas de comunicação utilizadas}

Foram detectadas no estudo diversas maneiras de expressão empregadas entre os ouvintes da instituição de ensino superior (acadêmicos, intérpretes ou professores) e os acadêmicos surdos:

Eu utilizo as mãos e tento falar lentamente com a colega surda. (AO1).

Com estudantes ouvintes, nota-se por meio das observaçôes a disponibilidade do surdo para empregar a escrita e a mímica, mas com preferência pela Libras. Isso se confirma no depoimento do acadêmico surdo:

[...] a comunicação pode ocorrer também por meio de escrita ou mímica, alguma coisa do tipo, agora, quando existe o conhecimento da lingua de sinais, a gente utiliza a lingua de sinais para essa comunicação e essa comunicação, ela pode nos ajudar a desenvolver mais. (AS3).

Lopes e Leite (2011) mostram em suas análises a preferência do uso da Libras pelo surdo, principalmente na comunicaçáo com ouvintes, mesmo que ainda utilizem de maneira rudimentar outros tipos de comunicação.

$\mathrm{O}$ estudo detectou que são comuns ainda nessa inter-relação a leitura labial e o gesto, sendo favorável ao surdo uma proximidade com o ouvinte, como indica o fragmento:

[...] tem as suas dificuldades na leitura labial, mas eu consigo me comunicar com os ouvintes dependendo do contato que eu tenho, se eu tenho vários contatos então eu consigo me comunicar melhor [...] (AS1).

O intérprete é bastante solicitado quando surgem dificuldades, já que Libras é a comunicação primordial dele com o surdo, sendo o professor aquele a requerer mais essa ajuda, pois reconhece bem o papel daquele profissional:

[...] uma das coisas que eu lanço muita ajuda e peço muita ajuda é através da intérprete [...] (P2).
Dorziat (1999) reconhece na língua de sinais a melhor maneira para se comunicar em substituição à linguagem oral utilizada pelos ouvintes, entretanto identifica como outras possíveis maneiras de estabelecer comunicação a oralidade, sinais, leitura labial, escrita, desenho, gestos, principalmente quando se trata da prática pedagógica. A autora refere que prover o surdo de uma comunicação total facilita a relação entre professor e aluno surdo.

Entretanto, reconhecer o surdo como pessoa surda e sua comunidade linguística assegura o reconhecimento das línguas de sinais numa perspectiva do bilinguísmo ${ }^{2}$.

\subsection{Libras, língua real e sólida de comunicação}

A língua de sinais é considerada pelos surdos do estudo uma forma de comunicaçáo perfeita, com a qual podem aprender em meio a outros surdos e ouvintes, como expressa o fragmento:

[...] é a minha língua, ela é $100 \%$ efetiva pra mim, por que eu posso aprender realmente com ela... ela facilita bem muito o meu conhecimento... (AS3).

Fávero e Pimenta (2006) fazem considerações à Libras como língua máe do surdo, sendo importante na elaboraçáo do conhecimento. Felipe (1997) exprime que, ao utilizá-la, é possível ao surdo a expressáo de conteúdos sutis, complexos ou abstratos, podendo-se discutir qualquer área do conhecimento, da Filosofia à Política, consolidando a comunicação.

Para alguns autores, o uso da Libras deve ser seguido do acesso à linguagem oral, visando facilitar o aprendizado e a comunicaçáo de pessoas surdas em um ambiente majoritário de ouvintes. Lacerda (2006), por exemplo, refere em sua pesquisa a proposta da educação bilíngue, que permite ao surdo a aquisiçáo da Libras primeiramente, facilitando o desenvolvimento das habilidades cognitivas e linguísticas para, em seguida, haver a inserção de uma segunda língua, majoritária em seu contexto social e escolar.

Nessa perpectiva, Lacerda e Santos (2013) notam a exposição da Libras para uma parcela da população que a desconhecia, como gestores, professores, colegas ouvintes e pais, bem como o acesso cada vez maior do surdo ao ensino superior, impulsionado, principalmente, pelo direito de ter intérprete em sala de aula. Tal direito é garantido pela legislaçáo referente à acessibilidade e ao reconhecimento da Libras como meio legal de expressão e comunicação das comunidades surdas brasileiras.

Ainda debatendo o tema tem-se a visão de um dos intérpretes da pesquisa, que revela suas impressōes 
acerca da Libras, considerando-a uma língua real e sólida, em detrimento de outras que não são efetivas quando se trata da comunicação entre surdos e ouvintes:

[...] devido a ela ser uma língua real, possibilita que qualquer tipo de mensagem seja transmitida de uma lingua para a outra sem haver nenhuma perda, mas outras formas utilizadas, principalmente da acadêmica surda com outros alunos ouvintes, às vezes não se faz entender completamente devido à falta de uma língua sólida de comunicação. (I2).

É importante observar que para uma comunicação efetiva entre surdo e ouvinte, mediada pela LIBRAS, faz-se necessária a presença do intérprete, caso o ouvinte não seja detentor do conhecimento da língua de sinais. Caso contrário, a oralização do surdo seria uma alternativa para facilitar a comunicaçáo.

Cita Lacerda (2007) que alunos ouvintes buscam se comunicar com os surdos tentando utilizar a Libras, valendo-se dos poucos sinais que conhecem ou requerendo auxílio do intérprete. Na pesquisa do autor, os alunos buscavam aprender os sinais com esse profissional. $\mathrm{O}$ conteúdo citado se fundamenta nas falas dos participantes ouvintes da pesquisa aqui tratada, quando questionados sobre as formas de comunicação utilizadas na interlocução com o acadêmico surdo.

Mímica e, às vezes, algum sinal que conheço. (AO2).

No caso do AS3, a comunicação se torna mais fácil por causa do intérprete. (AO3).

\subsection{O professor e suas dificuldades na inter-relação com o acadêmico surdo}

A pesquisa identificou dificuldades de comunicação e interação do professor para com o aluno surdo, de modo que o docente se acha impotente ante tal circunstância:

\section{[...] quando a AS1 chegou, que eu me deparei com a realidade de que na minha disciplina teria que ter uma forma de me comunicar com ela, eu me angustiei um pouco... (P1).}

Seno (2009) observou em sua pesquisa que professores demonstraram preocupação no atuar com alunos surdos, sendo o despreparo desses profissionais um dos fatores mais relevantes nas questôes referentes à inclusão educacional. Alguns sentimentos como medo, insegurança, ansiedade e angústia estão presentes no docente que necessita se adaptar à nova condição de ter em sala um estudante surdo.
Mediante as dificuldades de comunicação encontradas pelo professor em sala de aula, ele dá continuidade à sua rotina utilizando-se da linguagem oral que lhe é peculiar e deixa ao encargo do intérprete a função de passar o conteúdo ao aluno surdo.

[...] então eu continuei usando a oralização e ela sempre rejeitando esse tipo de comunicação, mas pela minha ignorância em termos da Libras eu continuei usando a oralização e o intérprete sempre me dando o suporte... (P1).

Além das palavras acima reveladas, tem-se nas observaçóes que a interação entre o aluno surdo e o professor irá variar, mas, para dois dos acadêmicos em estudo, isso acontece de maneira bastante singular, havendo comunicação quando da ocorrência de dúvidas, quase sempre por intemédio do intérprete.

Utilizando Rijo (2009), referencia-se o conteúdo citado, tendo em vista que o autor ressalta a presença do intérprete como meio para atual inclusão dos alunos surdos, sendo sua funçáo traduzir o que o professor está falando, enquanto esse último continua a explicação do conteúdo aos alunos ouvintes, esperando daquele profissional a realização de seu trabalho, alcançando a inclusão dos alunos surdos.

O professor do estudo em voga acredita que a melhor solução para a problemática da comunicação é a oralização do acadêmico surdo, mas entende que essa é uma decisão que compete apenas ao não ouvinte.

\section{[...] até hoje eu tento usar a oralização e vejo que eu posso dispor desse tipo de comunicação, apesar de hoje entender que é uma opção dela que mecanismo ela vai usar para se comunicar... E eu insisto na oralização. (P1).}

A dificuldade do professor quanto à comunicação com o aluno surdo é referida em estudo de Silva e Pereira (2003b), conteúdo no qual as professoras enfatizaram a necessidade de o surdo se comunicar oralmente e se aproximar do ouvinte utilizando a linguagem oral, reforçando que náo cabe a esse profissional se adequar às dificuldades do aluno surdo, que a adaptação deve vir do próprio aluno.

Em outra fonte mais recente, encontra-se a opinião de Gesueli (2006), que contrasta com ideias antes afirmadas. A autora discorre sobre a participação de professores surdos no trabalho educacional, afirmando que a língua de sinais é importante na constituição da identidade surda e que o trabalho de educaçáo dos surdos apenas terá êxito mediante a fluência do professor surdo em Libras ou do professor ouvinte também fluente. 
Referindo-se a uma dada experiência com aluna surda, uma professora participante da pesquisa corrente continua seu relato sobre a oralização:

\section{[...] mas a gente tem se comunicado algumas vezes através da oralização e não existe uma comunicação entre eu e ela na disciplina, por que ela se utiliza muito do intérprete como agente comunicador dela, então se torna difícil, às vezes eu tento usar o olhar, às vezes eu tento a oralização, tô de frente pra ela, junto com o intérprete, mas ela não interage comigo de forma nenhuma, ela só interage com o intérprete, apesar de algumas vezes aconteceu de faltar o intérprete e isso fez com que a gente entrasse em sintonia em alguns momentos. Eu achei que isso foi importante... (P1).}

Percebe-se no discurso a dicotomia sobre a real aceitação da preferência e liberdade do aluno surdo em escolher qual forma de comunicação utilizar no seu aprendizado. O professor destacou em outro momento que a escolha é do aluno, mas deseja que a oralização seja utilizada pelo acadêmico surdo mesmo com a presença do intérprete em sala de aula. Isso reforça a preferência pela oralizaçáo.

Dorziat (1999) reporta-se acerca da atuação do professor com um aluno surdo, assinalando que poderá até ser habilidoso na tentativa de se comunicar e ensiná-lo, mas sempre irá imprimir sua visão de ouvinte à língua de sinais, merecendo uma formação especial para melhor conduta com o surdo, pois não tem em sua grade curricular princípios da língua de sinais. $\mathrm{O}$ autor ainda refere que o professor adota uma visão baseada no princípio da "normalidade" e "adaptação à sociedade", não sendo possível àquele desvencilhar-se de valores socialmente constituídos, deixando-os influenciarem sua prática.

Acerca do tema oralização, Lacerda (1998) infere que contrapondo-se a esse modelo tem-se a educaçáo bilíngue, que aceita o canal visogestual como de grande relevância para a aquisição da linguagem da pessoa surda. A ideia é que sejam utilizadas duas línguas, a de sinais e, secundariamente, a língua do ouvinte ou majoritária. Segundo o autor, o surdo é passível de maior aceitação e adaptação à língua de sinais, pois conta com a integridade visogestual.

\subsection{Cultura surda e o papel do intérprete no contexto educacional}

Há divergências quanto à presença do intérprete em sala de aula. $\mathrm{Na}$ opiniáo do docente, o excesso de estímulos como: olhar para o intérprete, para o professor, para o quadro, caderno, compromete a atenção do acadêmico e, consequentemente, sua aprendizagem. O professor ainda coloca em questão a integridade da informação repassada pelo intéprete ao acadêmico surdo, tendo em vista que esse profissional não é da área em estudo.

[...] muitas vezes, ele fica dividido, não sabe ao certo se copia, se presta atenção, por que tem de ficar olhando para o intérprete e deixa de focar no que eu tô explicando, muitas vezes, e há, em alguns casos, essa dificuldade até do intérprete, por não ser da área, de entender perfeitamente os conceitos e transmiti-los de uma forma integra, de forma total, então, em muitos casos há uma certa deficiência em relação a isso. (P3).

Bisol et al. (2010) cita a percepção de um estudante surdo sobre o assunto. $\mathrm{O}$ autor revela a existência de uma situação delicada, na qual o aluno sugere que eventualmente o intérprete venha a fazer uma "seleçáo" do que é ou não adequado para o aluno perguntar, passando o intérprete da função de mediador a uma barreira na relação entre professor ouvinte e aluno surdo. Outros jovens consideram a presença do intérprete fundamental, mas relatam dificuldades relacionadas à capacitaçáo dos profissionais, principalmente no ensino superior, onde se deparam com a complexidade e especialização das diferentes áreas do conhecimento.

Lacerda (2006) infere que a presença do intérprete em sala de aula objetiva tornar os conteúdos acadêmicos acessíveis ao aluno surdo, além disso objetiva-se com o trabalho escolar o desenvolvimento do surdo nos quesitos aprendizagem, desenvolvimento do conteúdo acadêmico, de linguagem e social etc. Não basta ao intérprete apenas traduzir conteúdos, mas torná-los compreensíveis, fazendo sentido para o aluno, verificando a aprendizagem do aluno. Para a autora, é inerente ao papel do intérprete a função de também educar o aluno surdo.

Cantarino (2007, p. 7) reconhece que o intéprete interfere no conhecimento transmitido ao aluno surdo e revela: "interpretar não é um ato mecânico". Daí repercute a ideia de que a interação entre professor, intérprete e aluno surdo é importante, pois é uma questão pedagógica e não técnica.

Para o acadêmico ouvinte, a presença do intérprete e a língua de sinais são favoráveis à comunicação em sala de aula, requerendo sua ajuda na interlocução com o acadêmico surdo.

[...] quando tento falar com ela, noto que ela não consegue sem a ajuda do intérprete que a acompanha, mesmo com o esforço que tento fazer para me expressar. Acho eficiente a forma de comunicação através das mãos. (AO1). 
Lacerda (2000) faz inferências acerca do intérprete como possibilidade de inserção do aluno surdo nas classes regulares. Por meio desse profissional é possível receber informaçóes escolares na sua língua de domínio (Libras) por uma pessoa competente para isso, que serve também de apoio humano para atingir os objetivos escolares finais. Em experiência em sua pesquisa a autora presenciou uma atividade de leitura realizada por ambos os atores da sala de aula, surdos e ouvintes, em Libras, onde a dificuldade dos ouvintes na língua de sinais foi evidenciada e ao mesmo tempo superada com auxílio pelo intérprete. Demonstra-se com isso a importância desse profissional na intermediaçáo entre esses dois atores.

$\mathrm{O}$ acadêmico surdo reconhece que a Libras e a atuação do intérprete têm papel fundamental no seu aprendizado. É esse profissional que o capacita a compreender aquilo que é dito em sala de aula, seja referente ao conteúdo programático ou a qualquer outro que entre em voga.

[...] ter um intérprete na sala de aula facilita essa comunicação por que ele interpreta o que você quer transmitir, às vezes interpreta também o que o aluno me pergunta, alguma coisa, uma comunicação entre eu e alguns alunos, alguns universitários também ouvintes... a interpretação ou os sinais me ajudam a ter um rendimento melhor. (AS3).

O conteúdo acima revela que existe entre o surdo e seu intérprete uma relação de confiança, pois é com esse profissional que o acadêmico interage a maior parte do tempo em sala de aula. A comunicação em uma língua acessível a ambos facilita a interação e a aprendizagem do surdo. Com efeito, a inserção do intérprete como agente comunicador no âmbito da sala de aula funciona como um reconhecimento da sua importante função e determina o respeito à cultura surda.

Guarinello et al. (2008) alertam sobre a importância do intérprete em sala de aula, já que poderá minimizar as dificuldades dos surdos ante a desigualdade de línguas nesse espaço, por não haver uma língua que compartilhem com seus colegas e professores ouvintes. Pela presença do intérprete em sala de aula, o acadêmico poderá receber informações de maneira satisfatória, contando com um profissional capacitado para a função, de modo que o professor fica "livre" para ministrar sua aula sem a preocupação de transmitir a informação em sinais, enfatiza Lacerda (2009).

\subsection{Comunicação entre surdos e ouvintes}

No Brasil foi promulgada a lei de Libras - lei n. 10.436, de 24 de abril de 2002, que reconhece

[...] como meio legal de comunicação e expressão a Língua Brasileira de Sinais - Libras [...] forma de comunicação e expressão em que o sistema linguístico de natureza visiomotora, com estrutura gramatical própria, constitui um sistema linguístico de trasmissão de ideias e fatos oriundo de comunidades de pessoas surdas do Brasil. (BRASIL, 2002, p. 7).

Essas considerações dispóem sobre o valor da Libras como língua, agora amparada por uma legislação e, portanto, elemento reconhecido da cultura surda nos diversos contextos. Destarte, os primeiros relatos dos sujeitos participantes desta pesquisa ressaltam que muitos métodos podem ser utilizados na interlocução entre surdos e ouvintes. Ressaltam ainda os discursos que a presença do intérprete tem sido eficaz nesse momento, para que se desenvolva uma comunicaçáo efetiva e completa de significado. Entretanto, mesmo diante das dificuldades de comunicação, percebe-se que o aluno ouvinte busca se comunicar, ainda que de forma lenta, tenta fazer-se entender e compreende aquilo que lhe é dito, seja da maneira que for:

\section{[...] ele conseguiu entender e eu também entendi, embora uma comunicação muito lenta... tento falar devagar para facilitar a leitura dos meus lábios e fazer gestos para tornar mais fácil a compreensão. (AO3).}

Lacerda (2006) denomina o surdo como um estrangeiro que se mantém isolado do grupo mesmo que existam contatos e relacionamento amigável, pois faz uso de uma linguagem que amigos e professores não conhecem. Em seu estudo, as entrevistas revelam uma limitação na relação do aluno surdo com os demais companheiros, havendo troca de informaçóes básicas, que são confundidas com satisfatórias e adequadas.

Há também uma dificuldade em compreender a cultura surda e, consequentemente, a liberdade de escolha do acadêmico surdo quanto à língua que utilizará para se comunicar no ambiente universitário. Os professores deste estudo imprimem uma visão de ouvinte quanto ao uso da oralizaçáo e acesso à Língua Portuguesa na busca de uma comunicação mais efetiva: 
[...] sou de opinião que eles poderiam ser oralizados, eu acho que facilitaria muito essa interlocução com o professor, e também o ensino da Lingua Portuguesa, eu sou uma defensora de que o surdo deveria iniciar a aprendizagem da Lingua Portuguesa, mesmo porque facilitaria muito essa comunicação com o ouvinte. (P2).

Para os ouvintes, é mais prático utilizar a linguagem oral, do mesmo modo que é mais natural para o surdo utilizar a Libras.

Dizeu e Caporali (2005) também se posicionam sobre a temática referindo um predomínio da visão oralista sobre a língua de sinais e sobre a surdez. Fundamentam os autores que isso dificulta o processo de inserçấo social, que não condiz com a ideia de integração que defende o oralismo, ocasionando o silenciamento do surdo pelo ouvinte.

A partir das ideias apresentadas, percebe-se como a cultura surda deve ser mais bem difundida dentro dos espaços acadêmicos, visando atender as necessidades educacionais e sociais do surdo, ausentando-se o desrespeito à identidade deles. Cabe ao surdo fomentar suas escolhas acerca de quais formas de comunicação utilizar para se inserir na universidade e, futuramente, no mercado de trabalho.

Para Paula (2009), a constituição do sujeito surdo acontece por meio da língua de sinais e, com a sua legitimidade, constrói-se a identidade surda. O contato com a comunidade ouvinte e as dificuldades dessa interação podem favorecer que esses indivíduos assumam a identidade, pois ele se reconhece como diferente.

Lacerda (2006) ainda sinaliza que a relação dos surdos com os ouvintes não se revela sempre difícil, pois há aceitação de suas características, mas também nem sempre é fácil, já que existem dificuldades de relação, de conhecimento sobre a surdez e de aceitação de certas características. Quanto ao surdo, há o costume de se inserir em meio aos ouvintes e na presença do intérprete, porém a relação entre o aluno surdo e seus professores e colegas não é a mesma que o aluno ouvinte desenvolve.

\subsection{Comunicação com ouvintes e aprendizagem do surdo}

A comunicação entre surdos e ouvintes tem sua relevância, pois possibilita a inter-relação de indivíduos que participam do mesmo espaço, porém, não ajuda de forma plena na elaboração do conhecimento acadêmico do surdo. Os alunos surdos participantes deste estudo consideram que sua aprendizagem independe da comunicação com o ouvinte, mas é constituída em detrimento de seu desempenho na qualidade de aluno.

Eu acho que não, na verdade, às vezes, en é que fico buscando entender o que ele tá passando, às vezes uma atividade grupal, não é algo que vai me enriquecer, eu tento buscar, eu não vejo, assim, preocupação em tentar colocar algo que eu aprendesse. Já aconteceu de eu tá fazendo alguma coisa, algum atendimento errado ou manipulando algo de forma errada, dependendo da área de atuação é mais fácil de haver uma proximidade, uma interação, mas [em] outras áreas, quando tem um atendimento mais individual, eu entendo, assim, é cada um por si. (AS2).

Cruz e Dias (2009) discorrem sobre as dificuldades dos surdos no processo de escolarização universitária, relatando transtornos e sofrimentos. O surdo utiliza a leitura labial para tentar entender o que os ouvintes expressam, oralmente, em sala de aula, mas as modalidades utilizadas na interlocução não possibilitam uma comunicação que favoreça a reflexáo e a construção do pensamento abstrato, dificultando o avanço do processo humano e educacional. Debatem os autores que a problemática da comunicação e também o ambiente de sala de aula, como a disposição das cadeiras, impede o aluno de compreender o que está acontecendo. Essas dificuldades fazem o surdo acreditar que no ensino superior deve-se aprender por conta própria, ou seja, que ele é quem deve criar contextos educacionais para a sua aprendizagem.

A língua de sinais é parte fundamental no processo de aprendizagem, pois é mediante sua utilização que todo o conteúdo mental do surdo se formula e se transforma:

[...] quando eu tô oralizando ou quando eu tô com o intérprete, os dois eu consigo aprender, mas a lingua de sinais deixa mais claras as informaçôes do que o oralismo... Em lingua de sinais fica mais fácil, eu consigo pegar o contexto da aula, eu prefiro muito mais utilizar a língua de sinais do que o oralismo. (AS1).

Dizeu e Caporali (2005) lembram que os surdos se consideram pessoas usuárias de uma linguagem diferente, sendo que desejam ser vistos como pessoas capazes, que possuem suas particularidades, o que não os impede de crescerem e se desenvolverem da mesma forma que os ouvintes. De acordo com Peixoto (2006), a língua de sinais fornece suporte ao surdo no sentido de auxiliá-lo na interpretaçáo e produção das palavras, frases e textos da língua escrita. 


\subsection{Visões do intérprete e do professor sobre a aprendizagem do acadêmico surdo}

Os intérpretes desta pesquisa percebem o aprendizado do surdo como algo possível, podendo variar de surdo para surdo, pois ele demanda maior empenho por parte do acadêmico e depende também de sua fluência no uso da língua de sinais.

Varia de surdo para surdo. Irá depender do seu histórico escolar e [de] sua fluência na língua de sinais para poder acompanhar as aulas. No geral, os surdos conseguem assimilar e acompanhar os conteúdos. (I1).

Em estudo realizado com professoras do ensino regular, Silva e Pereira (2003b) se referem à opinião dessas profissionais quanto à aprendizagem do surdo, as quais consideram que esses alunos têm condições de aprendizagem normal. Algumas se utilizam dos termos normal e ilimitado, mas que a aprendizagem acontece de maneira diferente. Em comparação com ouvintes, afirmam que alguns desses alunos apresentam mais dificuldades que os surdos, mas que esses adquirem os conteúdos de maneira mais lenta.

Outro intérprete afirma que mesmo diante das dificuldades enfrentadas devido ao uso de uma língua diferente da oral e por estar em um ambiente prioritário de ouvintes, o surdo poderá aprender, principalmente quando o espaço universitário oferece estrutura adequada para esse propósito.

Eu acredito que o acadêmico surdo [...] tem dificuldades a serem superadas, mas se a instituição prepara um ambiente possivel para o seu crescimento ele é como qualquer outro aluno que pode, sim, se destacar, pode, sim, alcançar todos os objetivos comuns que existem para os acadêmicos no ambiente de ensino superior. (I2).

Rijo (2009) contribui com informação ao relatar que não é apenas a presença do intérprete em sala de aula, mediando a comunicação, que é suficiente para uma efetiva inclusão, havendo necessidade de um ambiente favorável às potencialidades do aluno surdo. O sistema de educação deve disponibilizar para as escolas recursos cabíveis ao processo de inclusão, caso contrário o aluno será integrado, porém não incluído.

Professor e intérprete, neste estudo, compartilham do pensamento de que os surdos devem procurar os próprios meios de chegar ao melhor rendimento:

[...] o aluno surdo, ele tem esse acesso a ter as disciplinas ensinadas na sua própria língua, mas isso vai depender muito do esforço do próprio aluno, por que o aluno ouvinte, ele também tem a aula, que é disponibilizada na sua própria lingua, que é a lingua oral, a Lingua Portuguesa, mas a gente percebe que muitos alunos, às vezes, não têm interesse, às vezes, faltam às aulas ou chegam atrasados. Por que existe um esforço da parte do aluno que deve acontecer, né? É por isso que é relativo, tem surdos que se dão muito bem [...] (I3).

O fragmento que se segue ressalta a visão do professor sobre o aprendizado do acadêmico surdo, considerando aspectos próprios das funçóes de qualquer estudante, mas que se faz mais necessário mediante a limitação de ser não ouvinte:

[...] Ele claramente tem uma dificuldade bem alta de absolver alguns conceitos, alguns conteúdos. $E$ [isso] exige dele, logicamente, um esforço, uma dedicação bem maior do que o normal. Alguns aspectos são vitais nesse processo, por exemplo, assiduidade, o estudo fora de sala, procurar ler, procurar outras fontes, procurar pesquisas sobre o assunto... E muitas vezes a gente não observa isso, o que se nota é que muitas vezes há um atraso na chegada à aula e isso dificulta ainda mais, levando-se em conta essa limitação que ele possui. (P3).

Silva e Pereira (2003a) posicionam-se sobre o tema revelando que muitos professores são favoráveis a não acreditar no potencial do aluno surdo, atribuindo as dificuldades à surdez. Além disso, os professores náo conhecem as implicaçóes decorrentes da ausência ou deficiência da audição e concluem:

Se o aproveitamento do aluno confirma a baixa espectativa do professor, é considerado deficiente e, com isso, o professor se isenta da responsabilidade de ensinar, pois é o aluno que não aprende.

$\mathrm{Na}$ visão dos professores participantes da pesquisa, as dificuldades enfrentadas pelos acadêmicos surdos são originadas por ocasião da linguagem em sinais, pouco comum para a maioria universitária, mas são possíveis de serem sanadas, sendo capaz a otimização quanto à aprendizagem do acadêmico surdo:

[...] eu acho que o aprendizado dela pode interferir de uma forma mais positiva, a forma dela interpretar o que se quer, o que se pede na avaliação, mas eu acho difícil, é complicado, ainda, eu vejo que o aprendizado dela tá um pouco deficitário por conta exclusivamente da questão da interação, em torno da comunicação... eu acho que ainda é deficitário. (P1). 
Olha, eu percebo de uma forma muito satisfatória, mas eu creio que isso poderia ser bastante otimizado, eu sou de opiniáo que eles poderiam ser oralizados... (P2).

Guarinello et al. (2006) fazem referência em seus estudos à opiniáo de professores quanto à aprendizagem dos alunos surdos, pois alguns comentavam que a aprendizagem era mais lenta e relacionavam essas dificuldades de aprendizagem à falta de linguagem. As autoras revelam, ainda, as modificaçôes necessárias ao ensino regular, segundo a opiniấo dos surdos, como: necessidade de intérpretes, a divulgação da Língua Brasileira de Sinais para a comunidade escolar e metodologias diferenciadas de ensino.

\section{Conclusões}

Por intermédio da língua de sinais é possibilitada ao surdo a aquisição de conhecimentos necessários ao seu desenvolvimento acadêmico, ou seja, à sua aprendizagem. Com a mediação do intérprete e dos sinais, o surdo se assegura em seu papel de estudante, pois mesmo inserido em um ambiente em que a língua majoritária é a oral, tem condiçóes de partilhar de sua cultura no contexto universitário.

Outros recursos da comunicação expressiva - como gestos, mímicas, escrita, desenho - e da comunicação compreensiva - como a leitura labial - facilitam a manutenção das relaçóes interpessoais e ajudam o acadêmico surdo em sua inserção no ambiente, porém não contribuem para seu aprendizado, pois as informaçóes são truncadas e, nesse sentido, não cumprem seu papel comunicador.

No ensino superior há necessidade de formar profissionais capacitados ao mundo do trabalho. De tal maneira, aprender conteúdos, manter relaçóes interpessoais, rotina de estudo e frequência às aulas faz parte desse âmbito. Quando o surdo aí se insere, é necessário que esteja preparado para incluir-se nesse espaço. Náo somente, no entanto, ele deve estar apto, pois a instituição que o receberá, bem como os professores, também hão de ter as aptidóes necessárias a essa inclusão. É relevante encontrar meios de prepará-lo de forma adequada sem entrar em conflito com sua cultura. Deverá ser aceito com seu método de comunicaçáo - Libras -, dispor de intérprete e professores capacitados e informados.

$\mathrm{O}$ acadêmico surdo tem seu papel e é responsável por sua formação profissional, devendo cumprir com seus deveres de estudante, sendo assíduo, pontual, interessado, estudando, buscando ajuda, sem receios, compreendendo suas limitaçóes sem deixar de se impor, de participar e de ser ativo.

Conclui-se que a comunicaçáo entre surdos e ouvintes impacta na aprendizagem do surdo no contexto da educaçáo superior. $\mathrm{O}$ assunto pautado, todavia, é abrangente, tem grande importância para o contexto educacional e traz consideraçóes acerca da cultura surda, da aprendizagem do surdo e de ambas, consequentemente, elas devem ser vistas no espaço acadêmico. Desse modo, trata-se de um conteúdo que demanda debates, que ainda merece atenção e exploração da comunidade surda e acadêmica.

\section{Referências}

BARDIN, L. Análise de conteúdo. Lisboa: Ediçôes 70, 1997.

BISOL, C. A. et al. Estudantes surdos no ensino superior: reflexôes sobre a inclusão. Cadernos de Pesquisa, São Paulo, v. 40, n. 139, p. 147-172, 2010. http://dx.doi.org/10.1590/ S0100-15742010000100008

BRASIL. Lei no 10436 de 24 de abril de 2002. Dispóe sobre a Língua Brasileira de Sinais - Libras e dá outras providências. Diário Oficial da República Federativa do Brasil, Poder Executivo, Brasília, DF, 24 abr. 2002.

BRASIL. Ministério da Educação. Censo da educação superior. Brasília, 2009. Disponível em: <portal.mec. gov.br>. Acesso em: 28 março 2011.

CAMPOS, J. Q. et al. Abordagem quantitativa da pesquisa de campo na saúde. São Paulo: Jotacê, 2001.

CANTARINO, C. Como a sociedade "não" enxerga os invisíveis e os surdos. Ciência e Cultura, São Paulo, v. 59, n. 3, p. 6-7, 2007.

CRUZ, J. I. G.; DIAS, T. R. S. Trajetória escolar do surdo no ensino superior: condiçôes e possibilidades. Revista Brasileira de Educação Especial, Marília, v. 15, n. 1, p. 65-80, 2009.

DIZEU, L. C. T. B.; CAPORALI, S. A. A língua de sinais constituindo o surdo como sujeito. Educação e Sociedade, Campinas, v. 26, n. 91, p. 583-597, 2005. http://dx.doi. org/10.1590/S0101-73302005000200014

DORZIAT, A. Sugestôes docentes para melhorar o ensino de surdos. Cadernos de Pesquisa, São Paulo, n. 108, p. 183-198, 1999.

FÁVERO, M. H.; PIMENTA, M. L. Pensamento e linguagem: a língua de sinais na resolução de problemas. Psicologia: Reflexão e Crítica, Porto Alegre, v. 19, n. 2, p. 225-236, 2006. http://dx.doi.org/10.1590/ S0102-79722006000200008

FELIPE, T. A. Introdução à gramática da LIBRAS. Série Atualidades Pedagógicas, v. 4, n. 3, p. 81-107, 1997.

GESUELI, Z. M. Lingua(gem) e identidade: a surdez em questão. Educaçâo e Sociedade, Campinas, v. 27, n. 94, p. 277-292, 2006. http://dx.doi.org/10.1590/ S0101-73302006000100013 
GIL, A. M. V. P. A aprendizagem no ensino superior. Revista Universidade de Guarulhos, Guarulhos, v. 7, n. 2, p. 20-22, 2002.

GUARINELLO, A. C. et al. A inserção do aluno surdo no ensino regular: visão de um grupo de professores do Estado do Paraná. Revista Brasileira de Educaçâo Especial, Marília, v. 12, n. 3, p. 317-330, 2006.

GUARINELLO, A. C. et al. O intérprete universitário da língua brasileira de sinais na cidade de Curitiba. Revista Brasileira de Educação Especial, Marília, v. 14, n. 1, p. 63-74, 2008.

LACERDA, C. B. F. Um pouco da história das diferentes abordagens na educação dos surdos. Cadernos Cedes, Campinas, v. 19, n. 46, p. 68-80, 1998.

LACERDA, C. B. F. O intérprete de língua de sinais em sala de aula: experiência de atuação no ensino fundamental. Revista Contrapontos, Itajaí, v. 5, n. 3, p. 353-367, 2009.

LACERDA, C. B. F. A prática pedagógica mediada (também) pela língua de sinais: trabalhando com sujeitos surdos. Cadernos Cedes, Campinas, v. 20, n. 50, p. 70-83, 2000 .

LACERDA, C. B. F. A inclusão escolar de alunos surdos: o que dizem alunos, professores e intérpretes sobre esta experiência. Cadernos Cedes, Campinas, v. 26, n. 69, p. 163-184, 2006.

LACERDA, C. B. F. O que dizem/sentem alunos participantes de uma experiência de inclusão escolar com aluno surdo. Revista Brasileira de Educação Especial, Marília, v. 13, n. 2, p. 257-280, 2007.

LACERDA, C. B. F.; SANTOS, L. F. Tenho um aluno surdo, e agora? Introdução à Libras e educação de surdos. São Carlos: EdUFSCar, 2013.

LOPES, M. A. C.; LEITE, L. P. Concepçóes de surdez: a visão do surdo que se comunica em língua de sinais. Revista Brasileira de Educação Especial, Marília, v. 17, n. 2, p. 305-320, 2011.

MAROSTEGA, V. L.; SANTOS, A. N. dos. A influência da comunicação que envolve família-filho-escola no processo de desenvolvimento e aprendizagem do sujeito surdo. Revista Educação Especial, Santa Maria, n. 28, p. 265-274, 2006.

MINAYO, M. C. S. O desafio do conhecimento: pesquisa qualitativa em saúde. 9. ed. São Paulo: Hucitec, 2006.

MUNGUBA, M. C. Videogame: estratégias de aprendizagem, visão do terapeuta ocupacional para o século XXI: aporte para terapeutas ocupacionais, educadores e pais. Fortaleza: Universidade de Fortaleza, 2002.

PAULA, L. S. B. de. Cultura escolar, cultura surda e construção de identidades na escola. Revista Brasileira de Educação Especial, Marília, v. 15, n. 3, p. 407-416, 2009.

PEIXOTO, R. C. Algumas consideraçôes sobre a interface entre a Língua Brasileira de Sinais (LIBRAS) e a Língua Portuguesa na construção inicial da escrita pela criança surda. Cadernos Cedes, Campinas, v. 26, n. 69, p. 205-229, 2006. http://dx.doi.org/10.1590/ S0101-32622006000200006

RAMPAZZO, L. Metodologia cientifica para alunos dos cursos de graduação e pós-graduação. 2. ed. São Paulo: Loyola, 2004.

RIJO, M. G. Q. A inclusão de alunos surdos nas escolas públicas de Passo Fundo. 2009. 48 f. Monografia (Especialização)-Instituto Federal do Mato Grosso, Cuiabá, 2009.

SENO, M. P. A inclusão do aluno com perda auditiva na rede municipal de ensino da cidade de Marília. Revista Psicopedagogia, São Paulo, v. 26, n. 81, p. 376-387, 2009. SILVA, A. B. P.; PEREIRA, M. C. C. A imagem que professoras de escola regular têm em relaçáo à aprendizagem do aluno surdo. Estudos de Psicologia, Campinas, v. 20, n. 2, p. 5-13, 2003a.

SILVA, A. B. P.; PEREIRA, M. C. C. O aluno surdo na escola regular: imagem e ação do professor. Psicologia: Teoria e Pesquisa, Brasília, v. 19, n. 2, p. 173-176, 2003 b. http://dx.doi.org/10.1590/S0102-37722003000200010

SMOLE, K. C. S; DINIZ, M. I. S. V. Comunicação em matemática: instrumento de ensino e aprendizagem. Revista Aprender On Line, Marilia, v. 2, n. 4, p. 20-22, 2002.

\section{Contribuição dos Autores}

Ambas as autoras realizaram a concepção do texto, pesquisa e sua redação, sendo a segunda autora a orientadora da pesquisa.

\section{Notas}

${ }^{1}$ Pessoa que traduz idiomas.

${ }^{2}$ Modelo de educação que propõe o ensino de duas línguas, a língua de sinais como primeira língua (L1) e, secundariamente, a língua do grupo ouvinte majoritário (L2). 